\title{
Prevalence of Rabies Pre-exposure Vaccination and Risk Perception among Veterinary Students at the University of Ibadan- A Cross Sectional Survey
}

\author{
Oluwafemi Adedayo Adetayo ${ }^{1, *}$, Olusade Cecilia Adetayo², Sulaimon Adisa Koleosho', Dayo Omodele Adeyemo³, \\ Oluropo Michael Obafemi ${ }^{4}$, Tolulope Ademola Olakojo ${ }^{5}$
}

\section{Oluwafemi Adedayo Adetayo $^{1, *}$, Olusade Cecilia Adetayo $^{2}$, Sulaimon Adisa Koleosho ${ }^{1}$, Dayo Omodele Adeyemo $^{3}$, Oluropo Michael Obafemi ${ }^{4}$, Tolulope Ademola Olakojo 5 \\ 'Department of Animal Health Technology, Federal College of Animal Health and Production Technology, Moor Plantation Ibadan, Park in Ibadan, NIGERIA. \\ '2London School of Hygiene and Tropical Medicine-College of Medicine Research Collaborative Center, University of Ibadan, NIGERIA. \\ ${ }^{3}$ Department of Disease Control, School of Veterinary Medicine, University of Zambia, ZAMBIA. \\ ${ }^{4}$ Department of Veterinary Laboratory Technology, Federal College of Animal Health and Production Technology, Moor Plantation Ibadan, Park in Ibadan, NIGERIA. \\ ${ }^{5}$ Livestock Improvement Programme, Institute of Agricultural Research and Training, Obafemi Awolowo University, Moor Plantation Ibadan, Park in Ibadan, NIGERIA.}

\section{Correspondence}

\section{Dr. Oluwafemi Adedayo Adetayo}

Department of Animal Health Technology, Federal College of Animal Health and Production Technology, Moor Plantation Ibadan, Park in Ibadan, NIGERIA. Mobile no: +2348030775974

Email: ibvirology@gmail.com

History

- Submission Date: 12-12-2020;

- Revised Date: 26-01-2021;

- Accepted Date: 03-03-2021;

DOI : 10.5530/ijmedph.2021.2.19

Article Available online

http://www.ijmedph.org/v11/i2

\section{Copyright}

(C) 2021 Phcog.Net. This is an openaccess article distributed under the terms of the Creative Commons Attribution 4.0 International license.

\begin{abstract}
Background: It is often mandatory for veterinarians and clinical veterinary students to receive rabies pre-exposure vaccination being among the occupational at risk group. The practice of encouraging veterinary students to receive rabies pre-exposure vaccination has the advantage of ensuring their safety during their clinical training and practice. The study examined the prevalence of rabies pre-exposure prophylaxis and rabies risk perception among veterinary students at the University of Ibadan. Materials and Methods: A well-structured questionnaire was used to obtain data from registered 325 veterinary students across all levels of study at 45 students per level of study using stratified random sampling method. Social Science Statistical Package 21 was used to analyze results. Results was presented as means, frequencies and percentages. Results: The mean age of respondents was $22.81 \pm 4.67$ years with $51.3 \%$ being male and $91.9 \%$ was single. The prevalence of rabies pre-exposure prophylaxis was extremely low, $18.6 \%$. Rabies risk perception was slightly high $62.5 \%$ among the respondents. Level of study and previous dog bite injury were statistically significant for rabies risk perception. Conclusion: There was non-compliance with the WHO recommendation that individuals at risk of rabies due to their occupational exposure should receive rabies pre-exposure prophylaxis. The University administration and Veterinary Council of Nigeria should make it known to be a policy for the clinical veterinary students.
\end{abstract}

Key words: Rabies, Pre-exposure prophylaxis, Risk perception, Veterinary students, University of Ibadan.

\section{INTRODUCTION}

Rabies is an infectious disease that is common in more than 150 countries and territories, with the greater risk of infection in Asia and Africa. ${ }^{1}$ Globally canine-mediated rabies causes around sixty-thousand humans deaths/ per annum, out of which about twenty-four thousand are contributed by African cases. ${ }^{1}$ The World Health Organization (WHO. 2018) detailed that the disease kills tens of thousands of individuals every year. ${ }^{2}$ Every year, there are an estimated 60000 fatal cases of rabies around the world, with almost $99 \%$ of cases occurring in Africa and Asia. $^{3}$ Additionally, it is a dangerous disease generally transmitted to people through bites and licks from infected animals, for the most part from domestic dogs. ${ }^{1-3}$ Rabies is one amongst the Neglected Tropical Infections that transcendently impacts poor and powerless populations who stay in rural areas. About $80 \%$ of human cases happen in rural regions. ${ }^{4}$

In 1912, Nigeria announced its first case of rabies. ${ }^{5}$ It is a persistent endemic issue as 10,000 yearly human cases are accounted for, in Nigeria only. ${ }^{5}$ The

disease keeps on being significant scourge of cats and dogs plateau state and Nigeria as a whole despite several attempts to control it. ${ }^{5}$ While considerable advancement has been made in the control and prevention of rabies, the rabies virus remains prevalent at high levels in dogs, in many regions. Dog vaccination is the most cost-effective way to prevent humans and livestock from transmitting the disease in regions where canine rabies is endemic. ${ }^{6}$ Nonetheless; significant underreporting of rabies cases implies that the real number of death is probably going to be higher. Poor and provincial populaces are excessively influenced, with the majority of deaths occurring in children younger than 15 years in Asia and Africa. ${ }^{6}$ Rabies is an avoidable yet deadly disease that is liable for around 59,000 death per year. ${ }^{7}$

Despite the endemic nature of the disease, the exact severity of the disease remains unclear. The disease has recently acquired a huge public interest of which a few endeavors were made by the public authority to evaluate the extent of the problem through mass immunization progrogrammes, surveillance 
Adetayo, et al.: Rabies Pre-exposure Vaccination and Risk Perception among Veterinary Students

approach and awareness programme in places with hot temperature where rabies activities are high. Case reports have been made despite all efforts by health authorities across the country to prevent the spread of the disease. ${ }^{8}$

Some erroneous beliefs and misconceptions can hamper the control of rabies in Africa. For instance, there is the belief that rabies is comparatively negligible as a public health threat disease; that rabies is an issue of 'stray' dogs that are not eligible for parenteral vaccination; that rabies can only be managed by killing or decreasing the population density of the dog; and that wildlife plays a major role in maintaining cycles of rabies in Africa. ${ }^{9}$ Cleverland et al. 2014 further submitted that misperceptions lead to a pattern of neglect, in which the execution of ineffective control measures prompts the demotivation of policymakers and veterinary field staff and energizes the mistaken impression that rabies control is worthless. ${ }^{9}$

Dog bites is the culprit behind approximately 100 percent of human rabies cases and, when symptoms start, the disease is usually fatal. ${ }^{10}$ Human rabies can be avoided through canine immunization to eradicate rabies at its source or by managing rabies vaccines and immunoglobulin after dog bite, scratches or exposure to saliva from suspected rabid dog (i.e. post exposure prophylaxis). ${ }^{10}$ Pre-exposure prophylaxis, which involves giving a progression of intramuscular or intradermal rabies vaccine injections to prime the immune system, is another preventive method. Once a person is re-exposed to the virus, this allows rapid recall of memory immune responses..$^{10}$ In addition, people who have gotten pre-exposure prophylaxis require less doses of post-exposure rabies vaccine and can be treated without rabies immunoglobulin, which is expensive and hard to procure. ${ }^{10}$ In spite of the fact that preventing rabies in dog is the most savvy method of preventing death from human rabies, pre-exposure prophylaxis is important for individuals at a high risk of the disease such as animal disease control staff and wildlife rangers, laboratory staff handling live rabies and rabies-related (Lysssavirus) viruses. ${ }^{11}$

Pre-exposure prophylaxis is also very important and necessary for Veterinary Medical students especially during clinical postings because, during this period, they normally come in contact with dogs and cats with unknown history of rabies vaccination. The practice of encouraging veterinary students to get vaccinated before their clinical posting has the advantage of ensuring their safety during their training in the Veterinary Teaching Hospital and outside of university practical posting. In addition, it guarantees that future veterinary staff have protection from rabies before entering a period of intensive exposure in the occupation. ${ }^{12}$ However challenges about persist among Veterinary students. For instance, according to Olugasa et al. at the University of Ibadan, Veterinary students have been neglected for rabies Pre-exposure prophylaxis (PREP) and those immunized were as a result of Postexposure prophylaxis (PEP) following a suspected rabid dog bite. ${ }^{13}$ Rabies pre-exposure vaccination coverage among veterinarian and students has significantly reduced for two decades now because of the financial constraint created on the university administration. ${ }^{14}$

Therefore, knowing PREP rabies vaccination status of the students is essential to be able to know how best to wade into the situation. It is on this premise that this study aims to assess the prevalence of PREP vaccination and determine factors associated with risk perception among veterinary students at the University of Ibadan, Nigeria.

\section{MATERIALS AND METHODS}

A quantitative cross sectional survey was conducted among the veterinary students in the faculty of Veterinary Medicine at the University of Ibadan between January and March 2017. The faculty was approved by the university governing council in June 1961 with the pre-clinical, para- clinical and clinical programmes. Veterinary Teaching Hospital was set up in October 1981 to coordinate the diagnostic and clinical services. The faculty currently has seven academic departments, a field Station at Eruwa, an Experimental Animal Unit and a National Zoonoses Research Centre. As at May 2016, University of Ibadan had produced a total of 2,020 veterinary graduates in 46 sets. A minimum sample size of 307 was expected to give the study significant results and power of $80 \%$. The student population was divided into 7 strata based on the level of study (100 level, 200 level, 300 level, 400 level, 500 level, 600 level and 700/800 level. Three hundred and twenty-five veterinary students which included attrition were therefore sampled at 45 participants per level of study. Inclusion criteria included current registered veterinary students at both undergraduate and postgraduate levels. Three hundred and nineteen returned their completed questionnaires and 12 were rejected due to incomplete information supplied making them invalid for analysis. The instrument was a self-administered questionnaire. It consists of 20 open and close-ended questions and was divided into three questions sections: Socio-demographic characteristics of the participants, history of rabies vaccination and risk perception of rabies. Statistical package for social sciences (IBM SPSS, New York) version 21 was used for data entry and analysis. Descriptive statistics technique was presented in frequency tables for variables. The items on risk perception were scored and each correct answer had 1 mark and maximum obtainable score of 25 marks which was converted to hundred per cent. Scoring for risk perception on rabies infection was categorized as follows: Low $=<50 \%$, High $=>50 \%$. Strongly agree $=5$, Agree $=4$, Undecided $=3$, Disagree $=2$, strongly disagree $=1$ where the answer is positive. Where the answer was negative, strongly agree $=1$, Agree $=2$, Undecided $=3$, Disagree $=4$, strongly disagree $=5$. Association between an independent variable and dependent variables was calculated using Pearson's ChiSquare. Further calculation of the strength of association and statistical significance between independent and dependent variables was assessed using Binary Logistic Regression analysis and $P<0.05$ was considered statistically significant.

\section{RESULTS}

A total of three hundred and seven veterinary students were interviewed. The oldest participant was 48 years old while the youngest was 16 years old. Many of them (42.7\%) were between 21-25 years old. The mean age of the respondents was $22.81 \pm 4.67$ years. More than half $163(51.3 \%)$ of the respondents were male and the marital status of majority $282(91.9 \%)$ was single. The predominant religion of the students was Christianity $(85.3 \%)$. Two hundred and fifty-seven $(83.7 \%)$ of the students belonged to the Yoruba ethnic group. Most of them had at least secondary education $173(56.4 \%)$. The prevalence of pre-exposure vaccination among the students was $50(18.6 \%)$ and university administration was responsible for the payment of only $5(8.6 \%)$ of the students while $41(70.7 \%)$ had Veterinary Council of Nigeria (VCN) paid for their preexposure vaccination (Table 1 ).

A large number of respondents had a low-risk perception of rabies. $115(37.5 \%)$ of the respondents disagreed and 135(44.0\%) strongly disagreed that their job could expose them to an animal bite. The majority disagreed $114(37.1 \%)$ and strongly disagreed $100(32.6 \%)$ that their chance of getting bitten by a dog was low. Very few $10(3.3 \%)$ disagreed and 188(61.2 \%) strongly agreed that rabies vaccination should be mandatory for veterinary students and staff. Hundred (32.6\%) disagreed and sixteen (5.2\%) strongly agreed that their job fit into" occupationally at-risk" group. Few respondents still strongly agreed $15(4.9 \%)$ and $10(3.3 \%)$ agreed that they cannot get infected with rabies even after bitten by a suspected rabid dog. (Table 2). 
Table 1: Socio-demographic characteristics.

\begin{tabular}{|c|c|c|c|}
\hline Variable & Category & Frequency $(n=307)$ & Percent \\
\hline \multirow[t]{6}{*}{ Age } & $<21$ & 111 & 36.2 \\
\hline & $21-25$ & 131 & 42.7 \\
\hline & $26-30$ & 45 & 14.7 \\
\hline & $31-35$ & 10 & 3.3 \\
\hline & $>35$ & 10 & 3.3 \\
\hline & Mean \pm SD & $22.81 \pm 4.67$ & \\
\hline \multirow[t]{2}{*}{ Gender } & Male & 163 & 53.1 \\
\hline & Female & 144 & 46.9 \\
\hline \multirow[t]{2}{*}{ Level of Study } & Preclinical & 185 & 60.3 \\
\hline & Clinicals & 122 & 39.7 \\
\hline \multirow[t]{2}{*}{ Marital Status } & Single & 282 & 91.9 \\
\hline & Married & 25 & 8.1 \\
\hline \multirow[t]{2}{*}{ Religion } & Christianity & 262 & 85.3 \\
\hline & Islam & 45 & 14.7 \\
\hline \multirow[t]{3}{*}{ Ethnic Group } & Yoruba & 257 & 83.7 \\
\hline & Igbo & 43 & 14.0 \\
\hline & Hausa & 7 & 2.3 \\
\hline \multirow{5}{*}{$\begin{array}{l}\text { Highest Level of } \\
\text { Education }\end{array}$} & HND and & 215 & 70.0 \\
\hline & below & 70 & 22.8 \\
\hline & DVM & 20 & 6.5 \\
\hline & $\begin{array}{l}\text { Master's } \\
\text { Degree }\end{array}$ & 2 & 0.7 \\
\hline & $\mathrm{PhD}$ and above & & \\
\hline \multirow{2}{*}{$\begin{array}{c}\text { Ever Received Pre- } \\
\text { Exposure Rabies } \\
\text { Vaccine }\end{array}$} & Yes & 57 & 18.6 \\
\hline & No & 250 & 81.4 \\
\hline \multirow{4}{*}{$\begin{array}{l}\text { If Yes Who Was } \\
\text { Responsible For The } \\
\text { Payment }(\mathrm{n}=57)\end{array}$} & University & 5 & 8.6 \\
\hline & Administration & 41 & 70.7 \\
\hline & $\begin{array}{c}\text { Veterinary } \\
\text { Council of } \\
\text { Nigeria }\end{array}$ & 11 & 20.7 \\
\hline & Self & & \\
\hline
\end{tabular}

Bivariate analysis of the association between selected variables and risk perception shows that level of study $(P<0.001)$, pre-exposure to dog bite $(P<0.01)$ and willingness to receive vaccination $(P<0.001)$ and age $(P<0.001)$ were found to be significantly associated with risk perception (Table 3).

After adjusting for possible confounders, the level of study became a risk factor of rabies risk perception among the students. $(\mathrm{OR}=\mathrm{O} .63$, $95 \% \mathrm{CI}=0.35-1.12, p=0.11)$. Pre-exposure to dog bite $(\mathrm{OR}=1.85$, $95 \% \mathrm{CI}=1.00-3.42, P=0.05)$ and willingness to receive pre-exposure vaccination $(\mathrm{OR}=2.86,95 \% \mathrm{CI}=1.37-5.96, P<0.01)$ were predictors to having high-risk perception about rabies (Table 4 ).

\section{DISCUSSION}

Findings from this study indicate that a large number of veterinary students at the University of Ibadan had not received rabies pre-exposure vaccination as recommended by CDC guidelines. ${ }^{15}$ More than fifty per cent of the respondents had the high-risk perception of rabies. Factors found to be associated with risk perception of rabies infection was the level of study, willingness to receive rabies pre-exposure vaccination, previous exposure to a dog bite.
The study showed that the mean age of veterinary students who participated in the study was $22.81 \pm 4.67$ years. Male respondents were slightly above $50 \%$. This is much lower than the findings of Daodu and Oluwayelu, 2016 on rabies knowledge and status of pre-exposure vaccination among veterinary students where about sixty-per cent of the students were males. ${ }^{14}$ In another Nigerian study by Odetokun et al. where the researchers attempted to assess knowledge of antimicrobial resistance among Veterinary students across universities, the study reported more veterinary male students. ${ }^{16}$ Therefore, the current study has revealed that females are gradually getting interested in the field of veterinary medicine. Results also showed that most of the respondents were Christians and very few were Muslims. The explanation for this is not unrealistic as Muslims have some beliefs about touching of dogs and pigs and there is no way one can avoid touching dogs and pigs as a Veterinarian.

According to the results of the current study, the majority of the veterinary Medical students had not received Pre-exposure rabies vaccine. Out of the few respondents who were immunized, the University Administration was responsible for the payment for half of them and one-tenth reported self-sponsored. Stratification of the level of the students into pre-clinical and clinical showed that even among those in clinical level, only a few had received rabies pre-exposure vaccination. This finding corroborates the findings of a previous Nigerian study by Dawodu and Oluwyelu. ${ }^{14}$ The authors indicated that more than eighty percent of the clinics' veterinary medicine students who participated in the study had not received Pre-Exposure rabies vaccine. This, therefore, means non-compliance with the WHO recommendation that individuals at high risk of rabies exposure, such as those at occupational risk group

Table 2: Risk perception among the veterinary students.

\begin{tabular}{|c|c|c|c|}
\hline Variable & Category & $\begin{array}{l}\text { Frequency } \\
(n=307)\end{array}$ & Percent \\
\hline \multirow{5}{*}{$\begin{array}{l}\text { My Job does not expose } \\
\text { me to animal bite }\end{array}$} & Strongly agree & 10 & 3.3 \\
\hline & Agree & 22 & 7.2 \\
\hline & Undecided & 25 & 8.1 \\
\hline & Disagree & 115 & 37.5 \\
\hline & Strongly disagree & 135 & 44.0 \\
\hline \multirow{5}{*}{$\begin{array}{l}\text { My chance of getting } \\
\text { bitten by a dog is very low }\end{array}$} & Strongly agree & 15 & 4.9 \\
\hline & Agree & 36 & 11.7 \\
\hline & Undecided & 42 & 13.7 \\
\hline & Disagree & 114 & 37.1 \\
\hline & Strongly disagree & 100 & 32.6 \\
\hline \multirow{5}{*}{$\begin{array}{l}\text { Rabies vaccination } \\
\text { should be mandatory for } \\
\text { veterinary students and } \\
\text { staff }\end{array}$} & Strongly agree & 188 & 61.2 \\
\hline & Agree & 68 & 22.1 \\
\hline & Undecided & 20 & 6.5 \\
\hline & Disagree & 10 & 3.3 \\
\hline & Strongly disagree & 21 & 6.8 \\
\hline \multirow{5}{*}{$\begin{array}{l}\text { My job does not fit into } \\
\text { occupationally at risk } \\
\text { group }\end{array}$} & Strongly agree & 16 & 5.2 \\
\hline & Agree & 17 & 5.5 \\
\hline & Undecided & 56 & 18.2 \\
\hline & Disagree & 100 & 32.6 \\
\hline & Strongly disagree & 118 & 38.4 \\
\hline \multirow{5}{*}{$\begin{array}{l}\text { I cannot get infected with } \\
\text { rabies even if bitten by a } \\
\text { suspected rabid dog }\end{array}$} & Strongly agree & 15 & 4.9 \\
\hline & Agree & 10 & 3.3 \\
\hline & Undecided & 43 & 14.0 \\
\hline & Disagree & 72 & 23.5 \\
\hline & Strongly disagree & 167 & 54.4 \\
\hline
\end{tabular}


Table 3: Association between risk perception and selected variables.

\begin{tabular}{|c|c|c|c|c|c|}
\hline \multirow[t]{2}{*}{ Variable } & \multirow[t]{2}{*}{ Category } & \multicolumn{2}{|c|}{ Risk perception } & \multirow[t]{2}{*}{ Chi square } & \multirow[t]{2}{*}{ Pvalue } \\
\hline & & $\begin{array}{c}\text { Low }(\%) \\
n=139\end{array}$ & $\begin{array}{c}\text { High (\%) } \\
n=168\end{array}$ & & \\
\hline \multirow[t]{2}{*}{ Age } & $<23$ & $149(80.5)$ & $31(25.4)$ & 92.13 & $<0.01$ \\
\hline & $\geq 22$ & $36(19.5)$ & $91(74.6)$ & & \\
\hline \multirow[t]{2}{*}{ Level of study } & Preclinicals & $100(71.9)$ & $85(50.6)$ & 14.48 & $<0.001$ \\
\hline & Clinicals & $39(28.1)$ & $83(49.4)$ & & \\
\hline \multirow[t]{2}{*}{ Gender } & Male & $72(51.8)$ & $91(54.2)$ & 0.17 & 0.68 \\
\hline & Female & $67(48.2)$ & $77(45.8)$ & & \\
\hline \multirow[t]{2}{*}{ History of exposure to PreP } & Yes & $27(19.4)$ & $30(17.9)$ & 0.12 & 0.73 \\
\hline & No & $112(80.6)$ & $138(82.1)$ & & \\
\hline \multirow[t]{2}{*}{ Pre-exposure to dog bite } & Yes & $19(13.7)$ & $45(26.8)$ & 7.93 & $<0.01$ \\
\hline & No & $120(86.3)$ & $123(73.2)$ & & \\
\hline \multirow{2}{*}{$\begin{array}{l}\text { Willingess to receive pre- } \\
\text { exposure vaccination }\end{array}$} & Yes & $111(79.9)$ & $155(92.3)$ & 10.11 & $<0.01$ \\
\hline & No & $28(20.1)$ & $13(7.7)$ & & \\
\hline
\end{tabular}

\begin{tabular}{|c|c|c|c|c|}
\hline Variable & Category & $\begin{array}{l}\text { Odds } \\
\text { ratio }\end{array}$ & $95 \% \mathrm{Cl}$ & $P$ value \\
\hline Age & $\begin{array}{l}<23 \\
\geq 22\end{array}$ & $\begin{array}{l}0.50 \\
\text { Ref }\end{array}$ & $\begin{array}{l}1.37- \\
5.96\end{array}$ & 0.02 \\
\hline Level of study & PreclinicalClinicals & $\begin{array}{l}0.63 \\
\text { Ref }\end{array}$ & $\begin{array}{l}0.35- \\
1.12\end{array}$ & 0.11 \\
\hline $\begin{array}{l}\text { Pre-exposure to } \\
\text { dog bite }\end{array}$ & $\begin{array}{l}\text { Yes } \\
\text { No }\end{array}$ & $\begin{array}{l}1.85 \\
\text { Ref }\end{array}$ & $\begin{array}{l}1.00- \\
3.42\end{array}$ & 0.05 \\
\hline $\begin{array}{l}\text { Willingess } \\
\text { to receive } \\
\text { pre-exposure } \\
\text { vaccination }\end{array}$ & $\begin{array}{l}\text { Yes } \\
\text { No }\end{array}$ & $\begin{array}{l}2.86 \\
\text { Ref }\end{array}$ & $\begin{array}{l}1.37- \\
5.96\end{array}$ & $<0.01$ \\
\hline
\end{tabular}

among whom veterinary clinical students belong. The reason being that clinical students rely solely on the University administration and the Veterinary Council of Nigeria. During the study period, only those in the 600 level and above had received the vaccine. Those in 500 level were waiting for the above-described authorities to take responsibility for their vaccination despite knowing the risk involved as clinical students who often come in contact with animals whose rabies vaccination status are unknown. It is therefore pertinent to suggest that governmental and non-governmental organizations intervene in providing free or subsidized anti-rabies vaccines so that these students can be vaccinated before rabies exposure. In fact, after graduation, veterinary clinical students rely so much on their rabies pre-exposure immunization status during posting for National Youth Service Corps (NYSC) in rural and underserved areas where immediate access to rabies post-exposure vaccination in case of dog bite injury may be challenging.

More than fifty per cent of the students had a high-risk perception of rabies. Many of the students felt their job could expose them to animal bite that their chance of getting bitten by a dog was low and they also believed that rabies vaccination should be mandatory for veterinary students and staff. It was really surprising that some of the respondents although very few indicated that they cannot get infected with rabies even after bitten by a suspected dog. This is dangerous because veterinarians are saddled with the responsibility of taking care of animal health and therefore come in contact with sick an animal daily which increases their risk of exposure. Therefore, mandatory pre-exposure vaccination of individuals at risk of rabies especially clinical Veterinary Medicine students must be taken seriously. This is pertinent as almost three-quarters of the clinical students had a highrisk perception of rabies infection and many pre-clinical students had low-risk perception. It appears that the benefit of complying with Rabies pre-exposure immunization seems poorly appreciated by pre-clinical Veterinary students. Active advocacy is now needed among students to further educate them on the inherent risk and false impressions that may be held regarding their risk perception.

Bivariate analysis of the association between selected variables and risk perception revealed that level of study, pre-exposure to dog bite and willingness to receive vaccination was significantly associated with risk perception. Multivariate logistic analyses adjusting for possible confounders confirmed the level of study as a risk factor of rabies risk perception among the students. Our observation, suggesting that students in pre-clinical do not have training about restraining of animals and are not used to handling animals, unlike clinical students. Also, they might not have been trained in handling occupational hazards. Preclinical students have higher risk perception than clinical students. This may be due to their lack of experience in handling animals and fear of dogs. Preclinical students have not learnt animal restraint and therefore are likely to feel that handling dogs and other infected animals may pose a lot of risk to them. Clinical veterinary students are likely to have learnt above rabies disease epidemiology and therefore have a better understanding of risks associated with a dog bite.

The study has also shown that Pre-exposure to dog bite and willingness to receive pre-exposure vaccination were protective risk factors to having low-risk perception about rabies.

\section{CONCLUSION}

Prevalence of rabies pre-exposure vaccination was very low. Rabies infection risk perception was slightly high. It can therefore be concluded that the relevance of pre-exposure vaccination should be strengthened by the university administration and make it known to be a policy of the university. Lecturers should be encouraged on knowledge transfer 
to their students on preventive measures for occupational zoonotic infections. The university administration should hereby either include the cost of rabies vaccination in students' school fee at a subsidized rate or solicit for funds from external donors.

\section{ACKNOWLEDGEMENT}

We want to appreciate all the undergraduate and postgraduate veterinary medical students and staff of the Nigeria Premier University of Ibadan, who voluntarily participated in filling the questionnaire for the crosssectional survey and sincerely provided all information regarding their rabies vaccination status and their perception towards the successful compilation of data the study.

\section{CONFLICT OF INTEREST}

The authors declare no conflicts of interest.

\section{ABBREVIATIONS}

OR: Odds ratio; WHO: World health organization; CDC: Centre for disease control and prevention; NYSC: National Youth Service Corps; PREP: Pre-exposure prophylaxis; PEP: Post-exposure prophylaxis.

\section{REFERENCES}

1. Hampson K, Coupeville L, Lembo T, Sambo M, Kieffer A, Atitlan M, et al. Global Alliance for Rabies Control Partners for Rabies Prevention: Estimating the global burden of endemic canine rabies. PLoS Negl Trop Dis. 2015;9(4):e0003709.

2. World Health Organization. Zero by 30 : The global strategic plan to end human deaths from dog-mediated rabies by 2030. World Health Organization. 2018. Available from: www.who.int/rabies/resources

3. World Health Organization. WHO Expert Consultation on Rabies. Second report. World Health Organ Tech Rep Ser. 2013;1-139.4.
4. World Health Organization. Zero by 30: The global strategic plan to prevent human deaths from dog-transmitted rabies by 2030. June 2018. Available from: www.fao.org/3/a-i7874e.

5. Umoh JU, Belino ED. Rabies in Nigeria: A historical review. Intl J Zoonosis. 1978;6(1):41-8.

6. Knobel DL, Cleaveland S, Coleman PG, Fevre EM, Meltzer MI, Miranda ME, et al. Re-evaluating the burden of rabies in Africa and Asia. Bull World Health Organization. 2005:83:360-8.

7. World Health Organization. Rabies: Epidemiology and burden of disease. WHO 2016. Available from: https://www.who.int/rabies/epidemiology

8. Adedeji AO, Eyarefe OD, Okonkwo IO, Ojezele MO, Amusan TA, Abubakar MJ Why is there still rabies in Nigeria? A review of the current and future trends in the epidemiology, prevention, treatment, control and possible eradication of rabies. British Journal of Dairy Sciences. 2010;1(1):10-25

9. Cleveland $\mathrm{S}$, Beyer $\mathrm{H}$, Hampson $\mathrm{K}$, Haydon D, Lankester F, Lembo T, et al. The changing landscape of rabies epidemiology and control. Onderstepoort J Vet Res. ;81(2):731-9

10. World Health Organization (WHO) Rabies Factsheet. WHO. 2019. Available from: http://www.who.int/news-room/fact-sheets/detail/rabies.

11. Dodet B, Durrheim DN, Rees H. Rabies: underused vaccines, unnecessary deaths. Vaccine. 2014;32(18):2017-9.

12. Compendium of Veterinary Standard Precautions for Zoonotic Diseases. Prevention in Veterinary. National Association of State Public Health Veterinarians. Veterinary Infection. 2016;248(2):171

13. Olugasa BO, Odeniyi AO, Adeogun AO, Adeola OA. Antibody levels against rabies among occupationally exposed individuals in a Nigerian University. Veterinary Italiana. 2010;46(1):21-8.

14. Daodu OB, Oluwayelu DO. Rabies knowledge and pre-exposure vaccination status of clinical veterinary medicine students in Nigeria. Vom Journal of Veterinary Science. 2016;11:117-25

15. Centre for Disease Control and Prevention. Pre-exposure Vaccinations. CDC 2011. Available from HTTPS:// www. cdc.gov/rabies/specific_groups/travelers/ pre-exposure_vaccinations.

16. Odetokun IA, Akpabio U, Alhaji NB, Biobaku KT, Oloso NO, Ghali-Mohammed l, et al. Knowledge of Antimicrobial Resistance among Veterinary students and their Antibiotics use practices: A National cross-sectional survey. Antibiotics. $2019 ; 8(4): 243$

Cite this article : Adetayo OA, Adetayo OC, Koleosho SA, Adeyemo DO, Obafemi OM, Olakojo TA. Prevalence of Rabies Pre-exposure Vaccination and Risk Perception among Veterinary Students at the University of Ibadan- A Cross Sectional Survey. Int J Med Public Health. 2021;11(2):108-12. 